\title{
Borggård-1 \\ - ny stratigrafisk kerneboring på Bornholm
}

Af Arne Thorshøj Nielsen, Geologisk Museum, Københavns Universitet, Geocenter København, Kurt Klitten, Danmarks og Grønlands geologiske Undersøgelse, Geocenter København og Hans Peter Birk Hansen, Bornholms Regionskommune

\section{En $316 \mathrm{~m}$ dyb fuldt kernet boring} på Sydbornholm udført maj-juli 2006 leverer for første gang præcise oplysninger om lithologien og tykkelsen af de nedre kambriske formationer i området. Boringen skulle desuden vise sig at rumme flere spændende overraskelser, bl.a. blev det konstateret, at de stærkt vandførende kvartsitter er næsten dobbelt så tykke som oprindeligt antaget.

Som omtalt i GeologiskNyt 4/06 blev der i maj-juli udført en kerneboring på Sydbornholm igennem Nedre Kambrium. Projektet er sponsoreret af Geocenter København, Bornholms Regionskommune, Danmarks og Grønlands Geologiske Undersøgelse samt Sparekassen Bornholms Fond, Mærsk Olie \& Gas, Denerco, Tethys Oil og Wexco. En
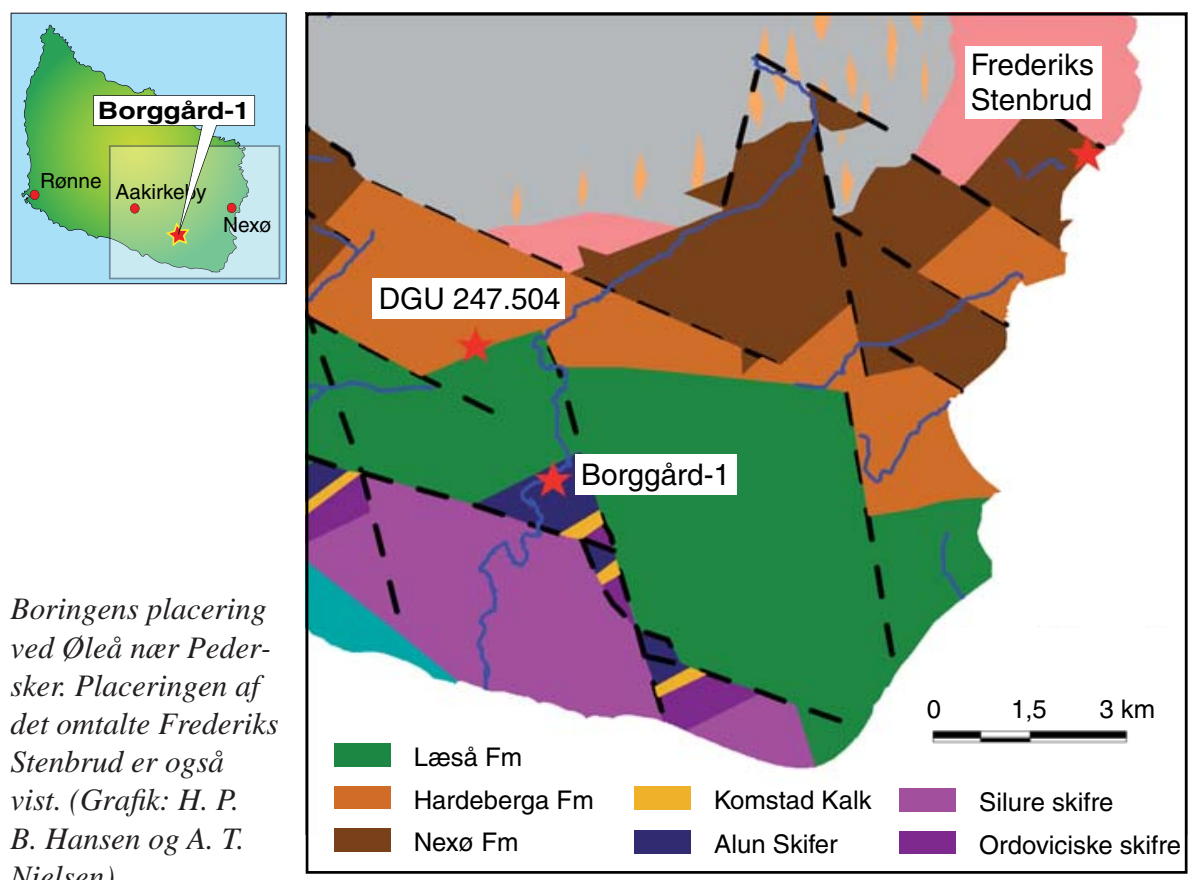

Boringens placering ved Øleå ncer Pedersker. Placeringen af det omtalte Frederiks Stenbrud er også vist. (Grafik: H. P. B. Hansen og A. T. Nielsen)

forklaring på den lange liste af sponsorer følger!

Boringens formål var dels at fastslå lagtykkelser og den præcise opbygning af Nedre Kambrium, dels at belyse grundvandets cirkulation på Sydbornholm. Geologer, der kender den hårde, kvartsitiske "Balka sandsten" bliver normalt forbavsede over at høre, at denne enhed repræsenterer det næstvigtigste grundvandsreservoir på Bornholm. Men hvor kommer vandet fra, når der pumpes?

\section{Boringen: Tykkelser versus kroner}

Nedre Kambrium på Bornholm har været genstand for talrige undersøgelser gennem de sidste par hundrede år, og eftersom Bornholm er det eneste sted i Danmark, hvor så gamle lag går i dagen, er den bornholmske lagpakke fast inventar i geologistudiet. Så alle geologer kender den røde Nexø sandsten, den kvartsitiske "Balka sandsten" og de "Grønne skifre", som slet ikke er skifre, men mere eller mindre sandede siltsten.

Men hvor tykke disse enheder er, og hvordan de varierer vertikalt og lateralt, har kun været kendt i grove træk, for blotningsgraden på Sydbornholm lader en del tilbage at ønske for en geolog. Tilmed er undergrunden opdelt $i$ en mosaik af små forkastningsblokke, så selv langs åerne kan man ikke nødvendigvis være sikker på, at successionen er reel.

For at få et bedre indblik i de "Grønne skifre" og denne enheds betydning for vandforsyningen på Sydbornholm blev der etableret et Geocenterprojekt i samarbejde med Bornholms Regionskommune, i hvilken forbindelse der skulle udføres en fuldt kernet boring igennem de "Grønne skifre". Boringen blev placeret ved Borggård lidt øst for Pedersker (figuren ovenfor), hvor Alunskifer fra Mellem Kambium kan ses i Øleåens brinker, og lagene kun hælder få grader. Tilmed er der ikke kendt større forkastninger i den umiddelbare nærhed, så borestedet forekom ideelt med henblik på at træffe de "Grønne Skifre" helt fra toppen. Dette viste sig heldigvis også at være tilfældet.

I de første faser af boringen gik alt stort set som forudsagt. Under et tyndt jorddække og lidt Alunskifer blev Nedre Kambrium antruffet allerede i 2,6 meters dybde og derefter blev "Balka sandstenen" nået i 109 meters dybde. I første omgang overså vi faktisk denne lithologiske grænse, for den stærkt bioturberede og urene øvre del af "Balka sandstenen" minder overfladisk om de "Grønne skifre" (se foto side 6).

Det formelle navn for "Balka sandstenen" er Hardeberga Formationen (se 


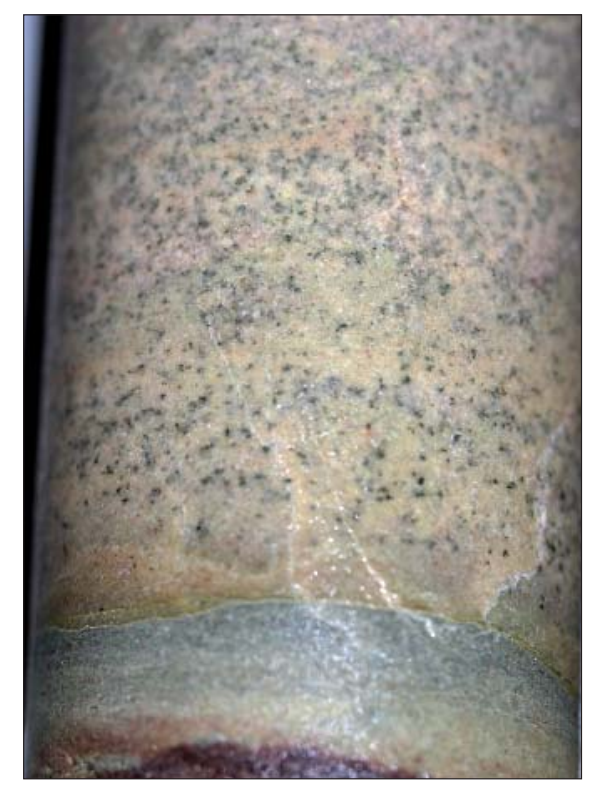

Indslag af formodet glaukonit i Gadeby Led ("nedre Nexø sandsten") ca. 15 m over basis. Glaukonit dannes kun marint og det lyse lag afspejler med stor sandsynlighed en kortvarig stigning i havniveau, der forte til oversvømmelse af flodsletten. (Foto: A. T. Nielsen)

nedenfor), så boremester Peter Turner fra Faxe Kalk startede med spøgefuldheder om "Softeberga", som vi ellers havde advaret om var en hård sag at bore i. Men hermed begik han hybris, og det kostede efterfølgende adskillige udslidte borekroner at bore i den knaldhårde "Balka sandsten", men nedad kom vi.

Det oprindelige budget indeholdt midler til at nå 150 meters dybde, men efter planmæssigt at være nået denne dybde var det simpelt hen for fristende ikke at forsøge at nå igennem hele "Balka sandstenen", der ifølge tidligere undersøgelser i en vandbo-

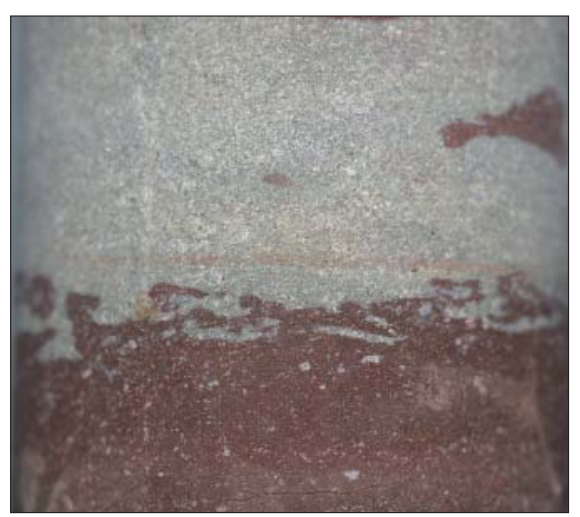

I et par niveauer af Gadeby Led ("nedre Nexø sandsten") ses strukturer, der sandsynligvis er gravegange. Der kendes ikke gravegange fra terrestriske miljøer i Fldre Kambrium, og det lyse lag afspejler enten en kortvarig stigning i havniveau eller vindstuvning under en storm, der førte til oversvømmelse af flodsletten. (Foto: A. T. Nielsen) ring (DGU 247.504, se kortet på forrigeside) kun 2,2 km væk fra borestedet burde være ca. $85 \mathrm{~m}$ tyk. Heldigvis var GEUS af samme opfattelse, så midler til at nå $50 \mathrm{~m}$ dybere blev bevilget.

Her begyndte den mangelfulde viden om Nedre Kambrium imidlertid at vise sig: Der var ingen Nexø sandsten i 200 meters dybde! Den nærliggende vandboring var fejltolket - cuttings ("stenmel" fra boringen) fra et tyndt rødt lag, tilmed midt i et tykt skiferindslag i "Balka sandstenen", var tolket til at repræsentere Nexø sandstenen (se foto på side 24).

En ekstra tillægsbevilling rakte til $50 \mathrm{~m}$ borekerne mere - men i 250 meters dybde stod borerøret i en mørkegrå, ren kvartsitisk sandsten. Vi var dog nået ned i den dårligt kendte, såkaldte "Gingham sandsten", der er delvist rødstribet (se foto på side 6), og som danner et overgangsled mellem Nexø og "Balka sandstenen". Så der burde ikke være langt til den rigtige Nexø sandsten.

$\mathrm{Nu}$ syntes GEUS imidlertid ikke, det var helt sjovt længere, og efter 2 fejlslagne boreprognoser kunne vi ikke fortænke GEUS $i$ at stoppe for yderligere bevillinger. Samtidigt var der på ingen måde tale om et fejlslagent projekt: Vi havde nået alle oprindelige mål og mere til - men ikke desto mindre var det jo frygteligt ærgerligt at skulle give op, for vi måtte være tæt på den rigtige Nexø sandsten.

Heldigvis skulle borefolkene på sommerferie, så der var 14 dages pusterum til at forsøge at skaffe yderligere midler. Målet var toppen af Nexø sandstenen - at komme igennem denne enhed, der formodedes at være 100-110 m eller mere, var helt udelukket.

Til vores egen store, men meget positive overraskelse lykkedes det i løbet af kun 2 uger og utallige telefonsamtaler og e-mails at få en ekstra finansiering på plads via velvillige bidrag fra olieselskaber og Sparekassen Bornholms Fond. Faktisk havde vi midler til $62 \mathrm{~m}$ ekstra borekerne, da operationen blev genoptaget efter sommerferien - og kort efter nåede vi endelig ned i den røde Nexø sandsten. Igen blev vi mindet om

\section{BORGGÅRD-1,Øleå, Bornholm}

\begin{tabular}{llll}
\hline & Alun Skifer & ++ & Grundfjeld \\
\hline- & Muddersten & $\ldots$ & Konglomerat \\
- & Siltsten &,$\quad$, & Glaukonit \\
$\square$ & Sandsten & F & Fosforit \\
& & & \\
\hline
\end{tabular}

Foreløbig lithologisk log af kernen fra Borggård. (Br = Brantevik Led, $R i=$ Rispebjerg Led). De nye lithostratigrafiske betegnelser er defineret af Nielsen \& Schovsbo, 2006.

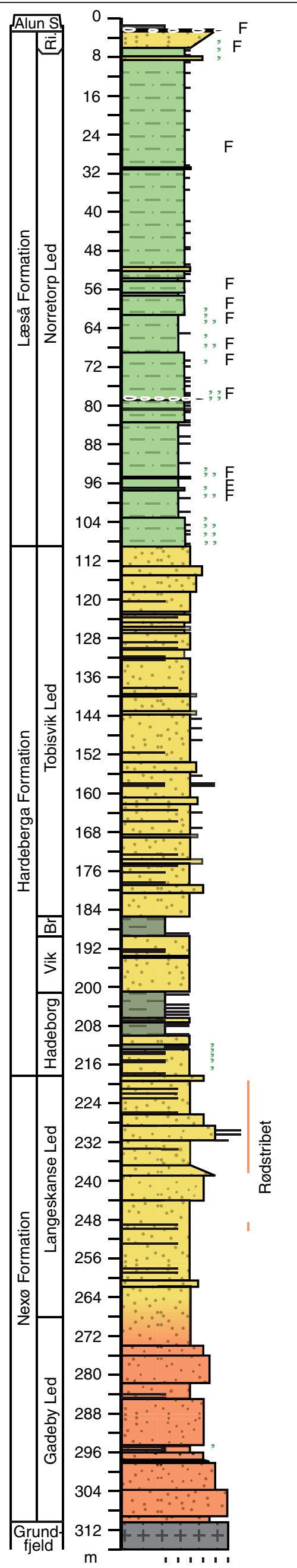


GEOCENTER forskningsboring Borggård (DGU nr. 247.627)

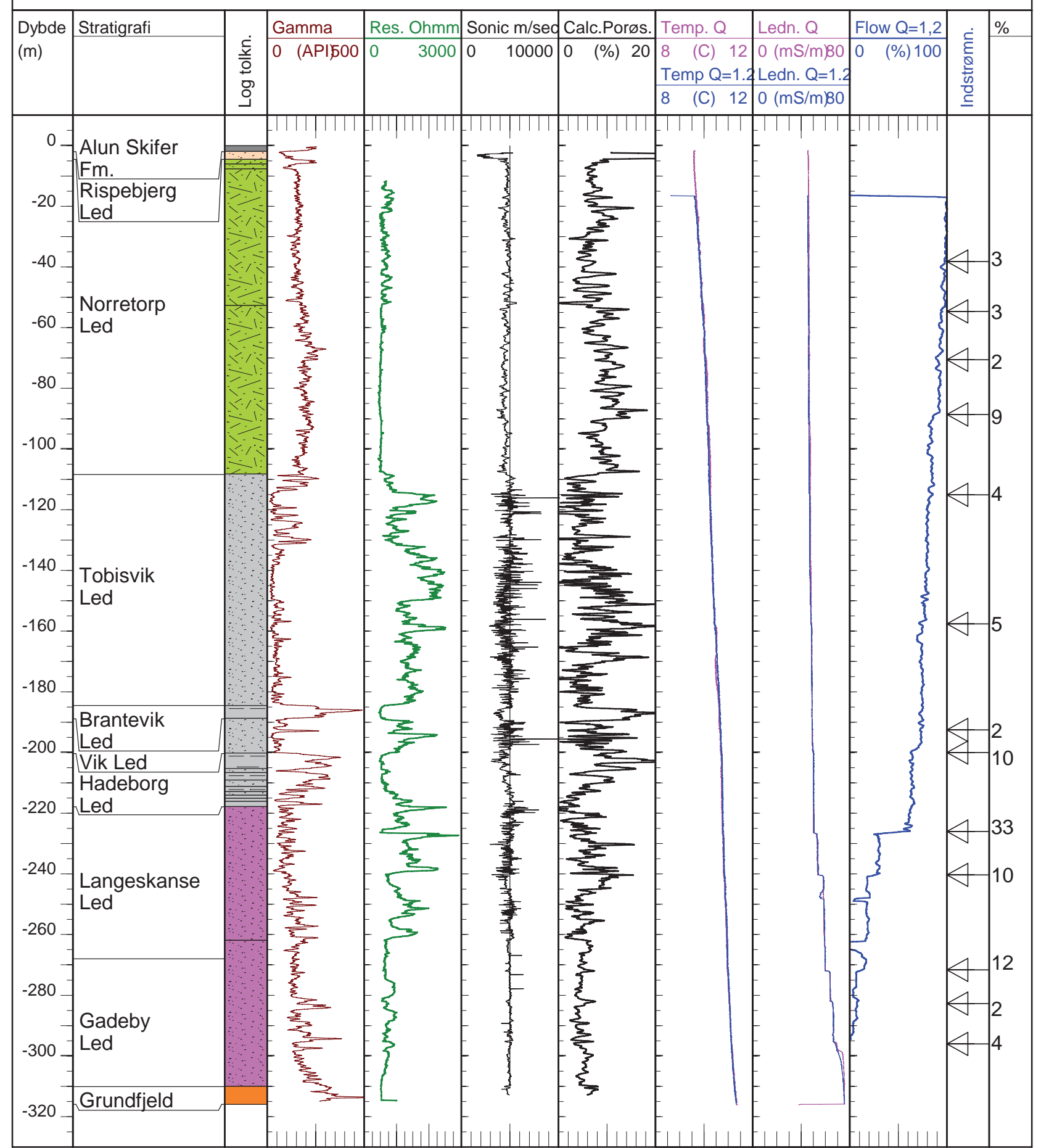

Geofysiske logs fra Borggård boringen, der vil udgøre et yderst vœrdifuldt vœrktøj til identifikation af lagfølgerne i ikke-kernede brøndboringer på Sydbornholm. Til højre er vist en flow-log, udregnet som \% af den samlede indstrømning. Det ses, at den største indstrømmning sker i Langeskanse Led (“øvre Nexø sandsten”). (Grafik: Kurt Klitten)

Nexø, der blev etableret 1754. Nexø sandsten er anvendt i mange ældre bygningsværker i København - og den tiltagende forurening samt almindelig slitage betyder, at mange af disse bygningsdele nu står foran en udskiftning. Men det er et problem, for den type Nexø sandsten, der brydes i øjeblikket og lejlighedsvis har været brudt i et stenbrud lige vest for Frederiks Stenbrud, repræsenterer ikke samme forholdsvis lyse stentype som den, der tidligere blev brudt $\mathrm{i}$ selve Frederiks Stenbrud. De nye stratigrafiske data fra Borggård-boringen viser, at successionen i Frederiks Stenbrud repræsenterer den øverste del af Gadeby Leddet, sandsynligvis inklusiv de nedre dele af overgangsintervallet mod Langeskanse Leddet.

Måske vil det være muligt via en revideret kortlægning baseret på loggede brøndboringer og geoelektrisk profilering at anvise et nyt sted til at åbne et stenbrud i den lyse type af Nexø sandsten, som der er behov for til renovering af bygninger i København. En sådan brydning kan formentlig ske lige vest eller sydvest for Nexø.

\section{Hydrogeologi}

Den oprindelige hensigt med Borggård boringen var at belyse de stratigrafiske og hydrogeologiske forhold i de "Grønne Skifre". 
opdeling i en "øvre" og en "nedre" enhed på basis af såvel gamma-loggen som resistivitets-loggen. Den øvre enhed (6-51 m i boringen, se figuren på side 7) udviser således en generelt lavere gamma-stråling og samtidigt en højere og mere varierende resistivitet end den nedre enhed (51-109 m). Ved sammenligning med den lithologiske $\log$ vist på side 19 ses den nedre enhed i modsætning til den øvre at indeholde niveauer med fosforit og glaukonit, som begge medvirker til den forhøjede gammastråling. Men den ensformige og lave resistivitet i den nedre enhed indikerer også et højere indhold af lermineraler end i den øre enhed, hvilket kan have betydning for denne enheds hydrauliske egenskaber.

Med hensyn til "Balka sandstenen" viser boringen, at enheden er ca. $25 \mathrm{~m}$ tykkere end hidtil erkendt. En efterfølgende gennemgang af tidligere borehulslogs udført af GEUS i vandindvindingsboringer viser, at den skifrede nedre del af "Balka sandstenen" (Hadeborg og Brantevik leddene) har været truffet tidligere (GEUS rapporter 2002/94 og 2005/45). Hydrogeologisk betyder den større tykkelse af "Balka sandstenen" imidlertid ikke, at voluminet af dette reservoir er øget, idet størstedelen af de nederste $25 \mathrm{~m}$ udgøres af skiferlag.

Derimod kan dokumentationen af, at Nexø sandstenen kan opdeles i en øvre ca. 49 m tyk overvejende kvartsitisk sandsten (Langeskanse Led) og en nedre ca. $43 \mathrm{~m}$ tyk overvejende rødfarvet subarkosisk sandsten
(Gadeby Led), få stor betydning for fremtidig planlægning af grundvandsindvinding på Sydbornholm. Baseret på logtolkning (se figuren side 7) kan "øvre Nexø sandsten" vises at have regional udbredelse, og genfindes eksempelvis i en $105 \mathrm{~m}$ dyb boring ved Lobbæk (DGU nr. 246.796; GEUS rapport 2005/45), lokaliseret ca. 10,5 km øst for Borggård, samt i en $87 \mathrm{~m}$ dyb boring (DGU nr. 247.323 i GEUS rapport 2002/94) ca. 3,5 km nordvest for Borggård. Det er i denne sammenhæng værd at bemærke, at der i denne "øvre Nexø sandsten" i alle tre boringer er påvist vandførende sprækker, jævnfør flow-log på side 7 samt de nævnte GEUS-rapporter. I betragtning af den store dybde til "øvre Nexø sandsten" i Borggård boringen, $219 \mathrm{~m}$ til $262 \mathrm{~m}$, er det bemærkelsesværdigt, at de to største indstrømninger observeres fra sprækker i henholdsvis 225 m (33\%) og 240 m (10\%) dybde.

Under borearbejdet blev der fra ca. 70 meters dybde og videre ned til bunden observeret overtryk i boringen. Betragtes forløbet af temperatur-, ledningsevne- og flow-logs fra bunden af boringen og opad, ses også mange zoner med indstrømning af vand, der foruden et øget flow hver især giver sig til kende ved et fald i såvel temperatur som ledningsevne i det opad strømmende vand. Uanset at der igennem mere end 25 år er foregået en større indvinding fra flere boringer ført ned i "Balka sandstenen" og beliggende kun nogle få kilometer nord for Borggård boringen, er der således

\section{Vandressource- administration}

For Bornholms Regionskommune er Borggård boringen en enestående chance for at opnå ny viden om Bornholms næstvigtigste grundvandsmagasin. De nye stratigrafiske data har allerede vist, at geologien i mange af vandforsyningsboringerne $i$ formodet "Balka sandsten" har været tolket forkert.

En bedre forståelse af, hvordan de tre nedre kambriske formationer på Sydbornholm er opbygget, har stor betydning for de fremtidige muligheder for at finde grundvandet og administrere udnyttelsen.

I sandstensmagasinerne er det en særlig udfordring at forstå vandets strømningsveje. Der findes således ikke et egentligt sammenhængende magasin, men mange systemer af sprækkezoner, der hænger mere eller mindre sammen og har forskellige trykniveauer. Det er derfor ikke muligt at udtegne et egentligt potentialekort for for eksempel "Balka sandstenen", men informationerne fra den nye boring kan forhåbentligt være med til at skabe en bedre forståelse af vandets (uransagelige) veje i sandstenen.

\section{"Balka sandstenen" - et umuligt reservoir}

Indtil 1974 havde geologer den opfattelse, at "Balka sandstenen" kun var ca. $60 \mathrm{~m}$ tyk. Man undgik så vidt muligt at udføre vandindvindingsboringer ned i enheden, idet de to brøndboringsfirmaer på Bornholm, Brd. Anker i Hasle og Lind i Åkirkeby, dengang stadig benyttede den gamle dieseldrevne slagboringsteknik. Med denne teknik var det en meget langsommelig proces at hamre sig ned gennem den hårde sandsten.

Men i 1974 blev brøndboringsfirmaet i Åkirkeby overtaget af en ung mand (Bjarne Pihl) uden større brøndboringserfaring, men med mod på livet. Under udførelse af en undersøgelsesboring (DGU nr. 247.322) ved Smålyngen for Åkirkeby kommunale vandforsyning $\mathrm{i}$ sommeren 1974 stoppede Bjarne Pihl derfor ikke med det samme, da han mødte den hårde sandsten i ca. $50 \mathrm{~m}$ dybde, men fortsatte $8 \mathrm{~m}$ ned. Her traf han på en vandførende sprække, som ikke alene havde artesisk vandtryk, men trykket var så stort (4 m over terræn) at boringen helt af sig selv producerede mere end $20 \mathrm{~m}^{3} /$ time.

Dette medførte, at Åkirkeby og Nexø kommuner i fællesskab i årene fra 1974 til 1976 gennemførte en række boringer i området Smålyngen nord for Pedersker med henblik på at undersøge og udnytte "Balka sandstenens" vandføringsevne. Den dybeste af disse boringer var $105 \mathrm{~m}$ (DGU nr. 247.349) og blev stoppet lige under et ca. $5 \mathrm{~m}$ tykt skiferlag efter at have gennemboret ca. 70 m "Balka sandsten".

Det skulle senere vise sig, at dette skiferlag er regionalt udbredt (= Brantevik Led). Alle boringer i Smålyngsområdet, der blev udført i årene 197476, påviste "Balka sandstenens" store vandføringsevne, og de blev efterfølgende indvindingsboringer for det nye vandværk "Smålyngen", der forsyner såvel Åkirkeby som Nexø.

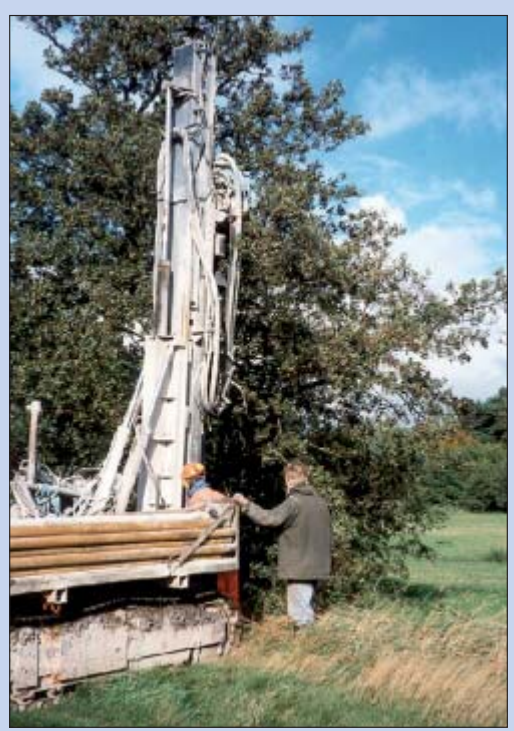

Aldre borerig af ncesten samme type som den Bjarne Pihl anvendte første gang, han borede ned i "Balka sandstenen". Her ses B. Pihl (iført grøn jakke) i fcerd med at bore ved Hundsemyre næer Snogebcek. (Foto: Hans Peter Birk Hansen) 


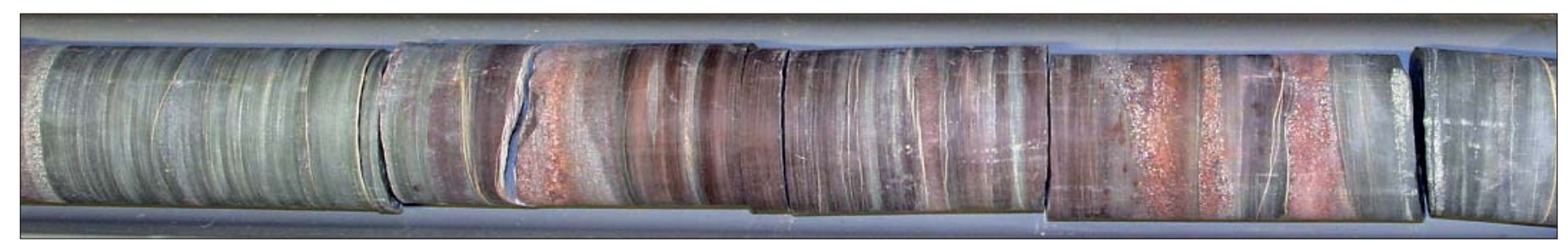

Brantevik Led markerer en meget markant stigning i havniveauet, og formodentligt var aflejringsdybden i Bornholmsområdet næer 100 m. Denne markante "drukne event” kan også ses i flere skånske sektioner. Enheden er ikke blottet på Bornholm, men kan let genkendes på gammaloggen i mange vandboringer (figuren på side 7). På Bornholm indeholder den øvre del af Brantevik Led en rødfarvet horisont, ca. 0,5 m tyk, med enkelte helt tynde sandlag. Cuttings fra disse rødfarvede lag blev fejltolket som Nexø sandsten i den ncerliggende vandboring (DGU 247.504) $i$ Pedersker Sandstensbrud, så man forud for Borggård-boringen troede, at "Balka sandstenen” var ca. 85 m tyk. (Foto: A. T. Nielsen)

stadig artesiske forhold i sidstnævnte boring i såvel Nexø Formationen som i "Balka sandstenen" og den nedre enhed af de "Grønne Skifre".

I betragtning af boringens store dybde og deraf følgende mange meter borekerne, forestår der et omfattende og tidskrævende arbejde med en detaljeret undersøgelse, omfattende mineralogiske og geokemiske analyser samt porøsitets- og permeabilitetsmålinger. Med hensyn til porøsitet er det overraskende, at Sonic-log'en indikerer 5-10 \% porøsitet i "Balka sandstenen" og den kvartsitiske "øvre Nexø sandsten”, hvorimod den samme log ikke overraskende indikerer en meget lav porøsitet i den "nedre Nexø sandsten" (0-2 \%). Dette vil blive nærmere undersøgt ved por/perm-bestemmelser af borekernen. Men det har længe været en gåde, hvordan man fysisk skulle forklare den barometereffekt på ca. $20 \%$, som kan observeres på vandstandsobservationer i vandforsyningsboringer ført ned i "Balka sandstenen" (Sørensen \& Hansen, 1976), idet en sådan effekt forudsætter en vis porøsitet af reservoirbjergarten (Barometereffekt $\mathrm{B}=\mathrm{n} * \gamma * \mathrm{~d} /(\mathrm{EW} * \mathrm{~S})$ hvor $\mathrm{n}$ er porøsitet, $\gamma$ porevandets massefylde, $\mathrm{d}$ reservoirbjergartens tykkelse, EW vandets elasticitetsmodul og S reservoirlagets magasintal).

Porøsiteten kan være både primær (intergranulær) og sekundær (sprækkebetinget), og det har hidtil været den almindelige opfattelse, at "Balka sandstenen" ikke havde bevaret primær porøsitet. Måske venter der også her en overraskende nyhed.
Referencer:

Jensen, F. T., Hinsby, K. og Clausen, E., 2002: Bornholms Amt - Udførelse af geofysiske borehulslogs i 10 boringer. GEUS Rapport 2002/94.

Klitten, K., 2005: Bornholms Regionskommune - Logging og vandkemi i vandforsyningsboringer, 2004. GEUS Rapport 2005/45.

Nielsen, A.T. \& Schovsbo, N., 2006: Cambrian to basal Ordovician lithostratigraphy in southern Scandinavia. Bulletin of the Geological Society of Denmark, vol. 53, pp. 47-92.

Sørensen, T. and Hansen, H. O., 1976:

Comprehensive Geohydrological Study of Consolidated Sedimentary Rcks in Bornholm. Nordic Hydrology, 8, 1977. 